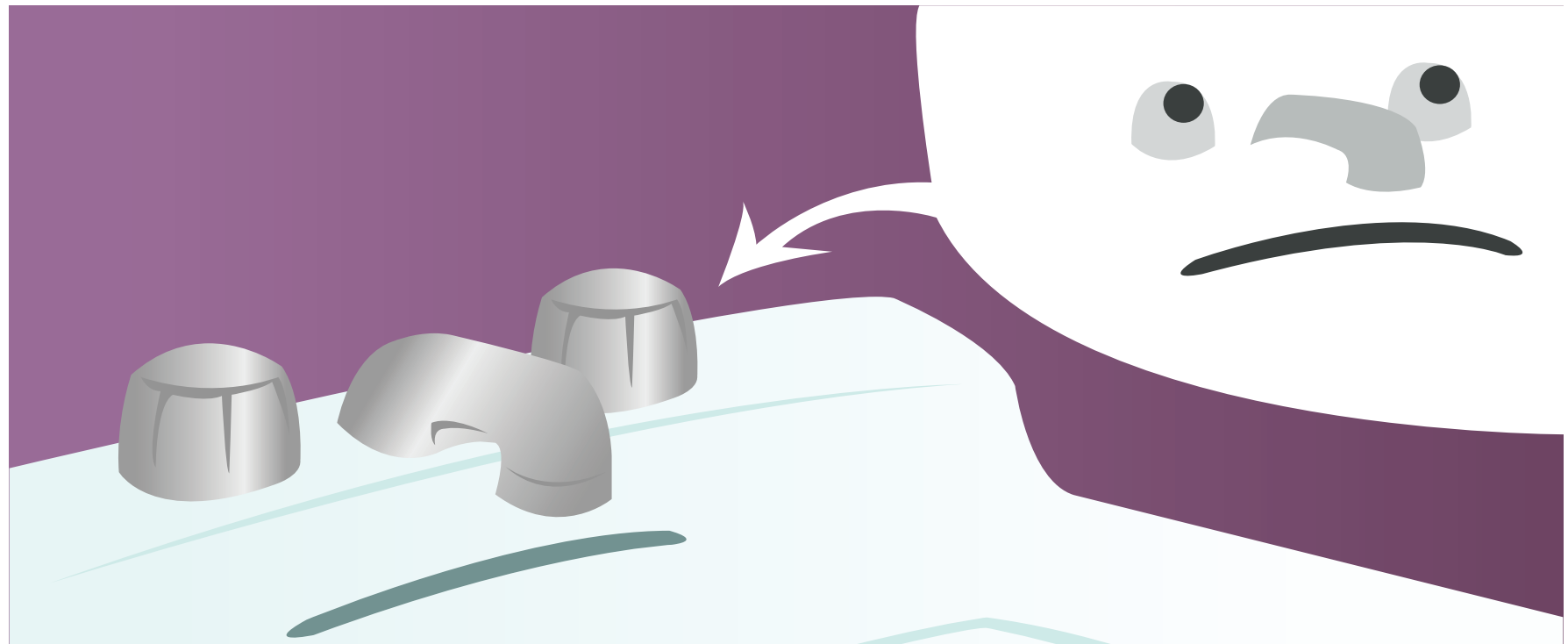

\title{
A FACE SCAVENGER HUNT: WHY WE SEE FACES IN OBJECTS WITHOUT FACES
}

\section{Mary Nevins ${ }^{1}$, Ashleigh Maxcey ${ }^{2 *}$ and Isabel Gauthier ${ }^{1}$}

${ }^{1}$ Vanderbilt University, Nashville, TN, United States, ${ }^{2}$ The Ohio State University, Columbus, OH, United States

\section{REVIEWED BY:}

MURCH

ELEMENTARY $S C H O O L$

AGE: 10-11
If you look around your classroom, you will see a room full of living things with faces: students, teachers, and maybe a class pet. However, have you ever noticed non-living things have a face when they shouldn't? For example, have you ever looked up in the sky and seen a face looking down at you in the clouds? Have you ever walked down the street and noticed a big grin on the front of someone's car? You might think these faces are just in your imagination but they can appear to all of us. Our brains are trained to notice faces, even in objects that do not actually have faces. Scientists have studied why we are able to see faces in non-face objects. In this paper, we explain some of the reasons why our brains are wired to see faces in everyday objects.

\section{WHAT IS GOING ON IN OUR BRAIN WHEN WE SEE A FACE?}

Our world has a lot of fascinating things for us to look at, but to understand why we see these things in the first place, it is useful to learn about how the brain makes it possible for us to see things. When you look at something 
TOP-DOWN

\section{PROCESSING}

describes the role our thoughts and expectations play in what we perceive.

\section{FACE PAREIDOLIA}

is when we see faces in objects that do not actually have real faces.

THE FUSIFORM FACE AREA

is an area of the tempora lobe that serves as the final stop in an assembly line where face parts are put together to make a face.

\section{FIGURE 1}

The image on the left shows a brain inside the head facing the left. This image was created using a method called magnetic resonance imaging that allows us to look inside the head to see the brain. The yellow lines through the brain are slices that we can look at to see the brain from a top-down view. The stacked images to the right are such slices through the brain, kind of like a stack of pancakes. The occipital lobe and the fusiform face area (FFA) are labeled in the slices. your eyes send a message to the brain with information about what you are looking at. Different parts of the brain will have to work together to figure out what all information means. For instance, if you see a dog running up to the playground at recess, you might be excited about the possibility that it is your dog, because it is the same size and color as your dog. You might even mistakenly think it really is your dog and that he has run away from home to come give you a kiss at school. Top-down processing is the technical term we use to describe what is happening when we tend to see what we want to see or what we think might be there. Top-down processing plays a key part in allowing our brains to go on a face scavenger hunt.

Face pareidolia (par-i-DOH-lee-a) is when we see faces in objects that do not actually have real faces. How is it that we can see an object come to life with a face? When the brain gets the message from the eyes with the information about what they are seeing, the message is sent to the occipital lobe, the part way in the back of the brain that deals with vision. When the message arrives in the occipital lobe, it is not yet organized into a face. Instead, the message is made up of information such as patterns of light and dark as well as edges. A process begins that is kind of like an assembly line that builds the face, where parts of the face are put together as it travels through the occipital lobe. As the assembly line finishes traveling through the occipital lobe, it carries the parts of the face that are being built to a different brain area, the temporal lobes, which are located behind the ears. In the temporal lobes, the information is put together into a complete picture, or the process of building the face is finished. The important area of the temporal lobe where this happens is called the fusiform face area (FFA) (Figure 1). In the FFA, the incoming information about face parts is put together like a puzzle to make one big picture that looks like a face.

If you look at a picture of the brain, it kind of looks like a pale walnut, bumpy with smooth edges. How can scientists figure out what different parts of the

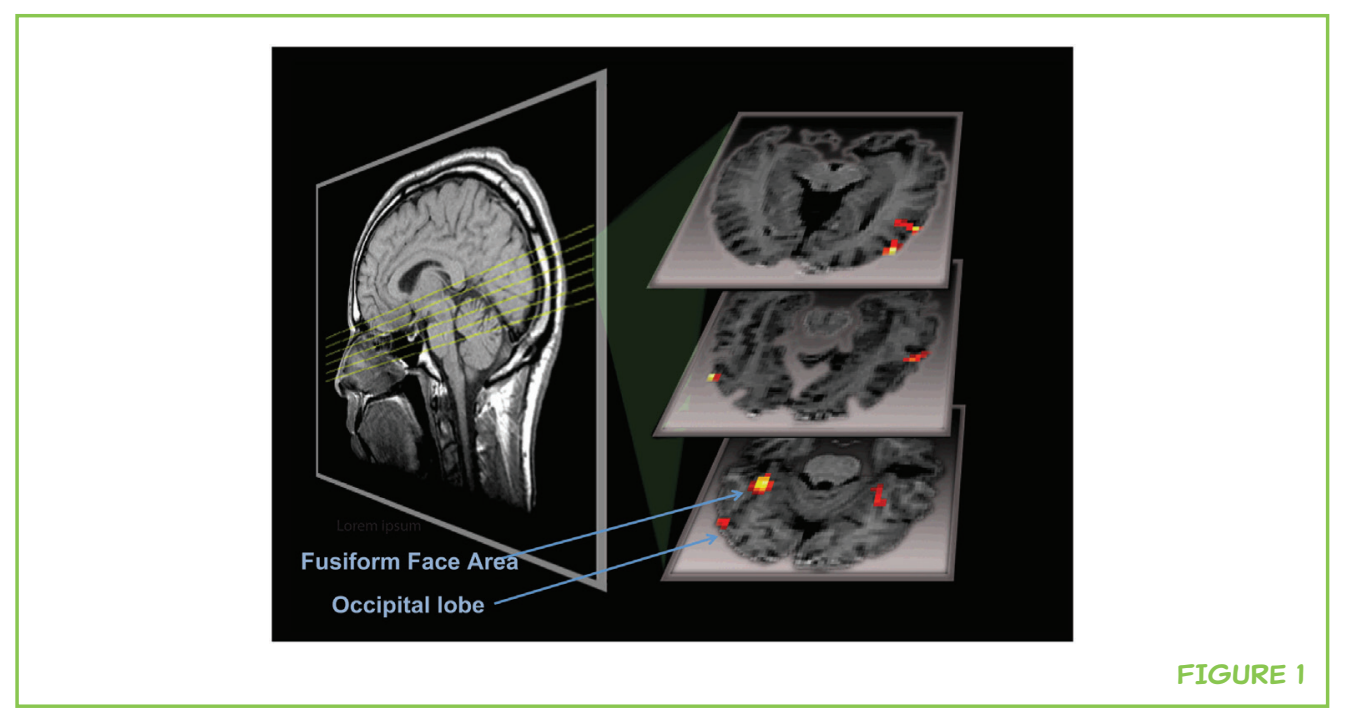


brain, like the FFA or the occipital lobe, do? Scientists use methods such as fMRI (which stands for functional magnetic resonance imaging) to see what is going on inside the brain. This method requires volunteers to lie still in a brain scanner that measures brain activity while the volunteers perform various tasks that they are asked to do by the friendly scientists. For instance, the FFA was discovered by asking volunteers to look at pictures of faces and objects, while the scientists looked (using fMRI) for brain areas that were more active when people looked at faces than when they looked at other objects.

One group of scientists was curious about whether the FFA is active when people are experiencing facial pareidolia [1]. After all, this is a situation in which people see faces, but they are looking at non-face objects. Specifically, scientists wondered if the brain area that is responsive to faces is active even when there is no actual face on the screen, but when a person reports seeing a face in an object. To answer this question, the scientists showed volunteers noisy, fuzzy images, like a TV screen with a bad signal, and sometimes the scientists included a faint image of a face in the noisy image and in other cases they included nothing at all. Volunteers were asked to guess if they could see a face in each image. The scientists found that the FFA was active when the people just thought they were seeing faces. So, when you experience seeing a face in the clouds, your brain activity is surprisingly similar to what it would be if you were really looking at a face!

\section{SEEING FACES KEEPS US SAFE}

Have you ever been playing outside and noticed a face popping out at you from the tree bark? Starting from birth, babies are immediately attracted to faces. Scientists were able to show this by having babies look at two simple images, one that looks more like a face than the other. By measuring where the babies looked, scientists found that the babies looked at the face-like image more than they looked at the non-face image [2]. Even though babies have poor eyesight, they prefer to look at faces. But why? One reason babies might like

\section{EVOLUTION}

means that all the kinds of living things that exist today, like people, developed from earlier forms of living things, which experienced changes that were made to help them survive. faces is because of something called evolution. Evolution involves changes to the structures of an organism (such as the brain) that occur over many generations. These changes help the organisms to survive. Some scientists, such as Carl Sagan, believe that face pareidolia helped humans survive because it made them alert to sneaky enemies [3]. By being able to recognize faces from afar or in the dark, humans were able to know someone was coming and protect themselves from danger.

\section{ARE WE BORN WITH A FACE DETECTOR?}

While humans may have evolved a visual system that can recognize faces, actual experience looking at faces is critical in order for the brain to become 


\section{CHUNKING}

is the term for when your visual system groups a bunch of smaller parts together to form a big picture.

\section{GESTALT}

\section{PRINCIPLES}

are basic rules that the brain uses for grouping information together. very interested in faces and very good at recognizing them. For years, people thought that humans were born with an FFA. However, a recent study in which scientists raised baby monkeys making sure they never saw a face revealed that, as a result, they had no FFA and they also did not look at faces more than other objects [4]. This study showed that experience with faces is required for us to become face experts. Other studies have shown that if we become experts at recognizing other objects, such as cars or birds, the FFA starts to respond to these other categories too [5].

\section{PUTTING THE PIECES TOGETHER}

So far, we have talked about how the brain has a special area that is used to see faces and why that might be useful based on evolution. Another reason why you might stare at the clouds and see faces is that the visual system is able to put together parts of non-face objects to create a full image. Chunking is the term for when your visual system groups a bunch of smaller parts together to form a big picture. Your visual system is constantly chunking smaller images, in order to organize the messages coming from the eyes. For example, when you see a mouth and eyes, you are able to put together a face. It is so natural for humans to chunk information in this way that scientists have even described a list of basic rules that the brain uses for chunking. This list of rules is called the Gestalt Principles, named after the Gestalt psychologists. One famous saying we still use that came from Gestalt psychology is "the whole is greater than the sum of its parts." This means that, sometimes, the way you group pieces of information gives the information more meaning than what was present in the individual pieces that you are grouping together, like a face in the clouds.

Two examples of the Gestalt Principles are proximity and similarity. Proximity means objects that are close together are seen as belonging to one group. In Figure 2A, proximity can help you see two rows of horses (that go from left to right) rather than four columns of horses (that go from top to bottom). Similarity means objects that are the same are seen as belonging to the same group. In Figure 2B, similarity helps you see the Legos in two columns (that go from top to bottom), grouped by color, rather than in four rows (that go from left to right).

\section{ACTIVITY: FACE SCAVENGER HUNT}

Are you curious where you might be able to find faces in the world around you? Ask your friends or classmates if they want to join you for a face scavenger hunt. This means you will go around your school or neighborhood in search of objects that look like faces. In Figure 3, we show some faces we found on campus at Vanderbilt University in Nashville, TN, USA. We saw a face in a bathroom sink, a leaf, and the front of a truck. When you go on a 


\section{FIGURE 2}

This figure shows two of the basic Gestalt grouping rules, proximity and similarity. A. Proximity-You see these horses as being in rows going from left to right with four horses in each. You do not see them as columns going up and down with two horses in each. This is because you are grouping together the animals that are closest to one another and the horses next to each other are closer than the horses above and below each other. B. Similarity - You see these Legos as one column of red Legos and one column of blue Legos because you are grouping them together by putting together the Legos with the same color.

\section{FIGURE 3}

Here are some pictures that we took around our school when we went on a face scavenger hunt. When we saw these objects, we thought they looked like faces. We have circled the faces in red on the right to help you see them.

\section{A<smiles>[PbH2]</smiles><smiles>C1=CC(C2CCC2)C2CCC1C2</smiles><smiles>C1=CC(C2CC2)C2CCC1C2</smiles>

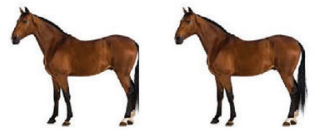

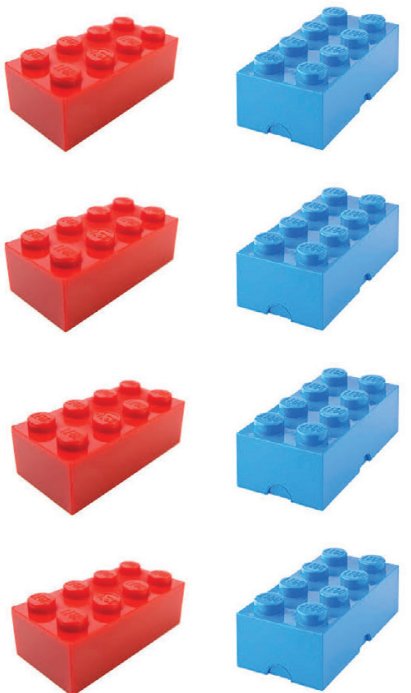

FIGURE 2

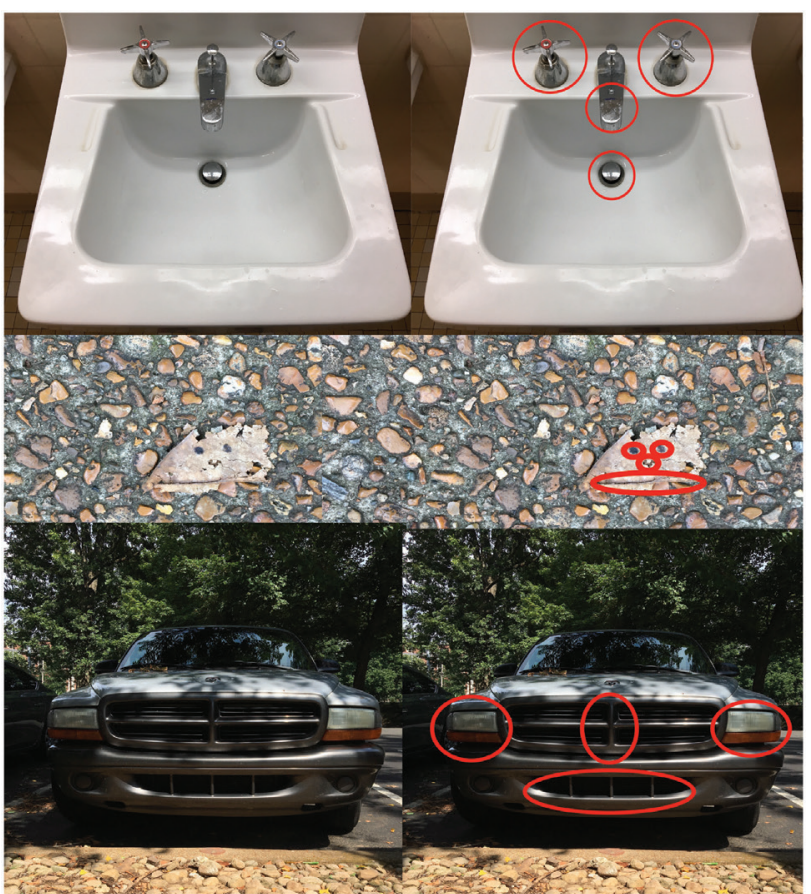


face scavenger hunt, you might want to take a camera with you and snap pictures of all the faces you find. When you finish, you can share and compare photographs with your friends.

\section{REFERENCES}

1. Liu, J., Li, J., Feng, L., Li, L., Tian, J., and Lee, K. 2014. Seeing Jesus in toast: neural and behavioral correlates of face pareidolia. Cortex 53:60-77. doi:10.1016/j. cortex.2014.01.013

2. Mondloch, C. J., Lewis, T. L., and Budreau, D. R. 1999. Face perception during early infancy. Psychol. Sci. 10:419-22. doi:10.1111/1467-9280.00179

3. Zimmerman, K. 2012. Pareidolia: Seeing Faces in Unusual Places. LiveScience.

4. Arcaro, M. J., Schade, P. F., Vincent, J. L., Ponce, C. R., and Livingstone, M. S. 2017. Seeing faces is necessary for face-domain formation. Nat. Neurosci. 20(10):1404-12. doi:10.1038/nn.4635

5. Gauthier, I., Skudlarski, P., Gore, J. C., and Anderson, A. W. 2000. Expertise for cars and birds recruits brain areas involved in face recognition. Nat. Neurosci. 3:191-7. doi:10.1038/72140

SUBMITTED: 13 September 2017; ACCEPTED: 30 November 2017; PUBLISHED ONLINE: 18 December 2017.

EDITED BY: Sabine Kastner, Princeton University, United States

CITATION: Nevins M, Maxcey A and Gauthier I (2017) A Face Scavenger Hunt: Why We See Faces in Objects without Faces. Front. Young Minds 5:67. doi:10.3389/frym.2017.00067

CONFLICT OF INTEREST STATEMENT: The authors declare that the research was conducted in the absence of any commercial or financial relationships that could be construed as a potential conflict of interest.

COPYRIGHT () 2017 Nevins, Maxcey and Gauthier. This is an open-access article distributed under the terms of the Creative Commons Attribution License (CC BY). The use, distribution or reproduction in other forums is permitted, provided the original author(s) or licensor are credited and that the original publication in this journal is cited, in accordance with accepted academic practice. No use, distribution or reproduction is permitted which does not comply with these terms.

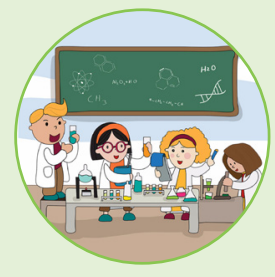

\section{REVIEWED BY}

\section{MURCH ELEMENTARY SCHOOL, AGE: 10-11}

Mrs. L's fifth Grade Class is a group of inquisitive and engaged students that are very interested in learning about the brain. Through conversation, questions, and looking at different brains, these students led a lively discussion about the intricacies of how the brain works. 


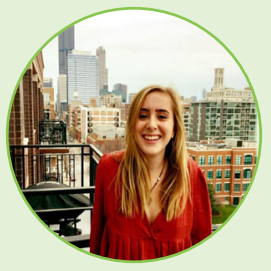

\section{AUTHORS}

\section{MARY NEVINS}

I am an undergraduate at Vanderbilt University studying Psychology. I am fascinated by the abilities the brain has and how it is still an unsolved mystery. I spend a lot of time in the Music Cognition Lab at school doing research. I enjoy playing and writing music, hiking, and spending time with friends and family. I am participating in a study abroad program in Dublin, Ireland because I love to travel and want to immerse myself in a new culture.

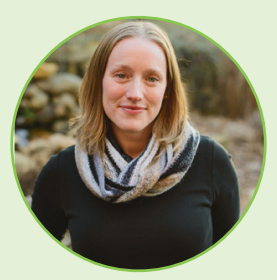

\section{ASHLEIGH MAXCEY}

I am a Visiting Associate Professor of Psychology at The Ohio State University in Columbus, Ohio, USA. I love my job because I get to be a teacher (of wonderful students like Mary Nevins) and a scientist at the same time. In my laboratory, I ask questions about how people remember and why they forget. I think these are topics that everyone finds interesting since we all try to remember some things and forget others. I love traveling with my family to places we have never been. I feel most at home when I am on an airplane, starting a new adventure, with my three kids and my husband. *ammaxcey@gmail.com

\section{ISABEL GAUTHIER}

I am a Professor of Psychology at Vanderbilt University in Nashville, Tennessee, USA. I love the collaborative aspects of science, the challenges of asking new questions and trying to come up with creative ways to answer them. I am interested in why some people are better at recognizing objects than others, and how experience changes our ability to perceive the world. I am trying to learn guitar and I enjoy martial arts, cooking, and reading books that are strongly recommended by friends. 